\title{
Modeling the Influence of Climate Factors on Malaria Transmission Dynamics in North Kordofan State, Sudan
}

\author{
Hamid H. Hussien \\ Department of Mathematics, College of Science \& Arts, King Abdulaziz University, Rabigh, Saudi Arabia \\ Email: hamid128@yahoo.com
}

How to cite this paper: Hussien, H.H. (2020) Modeling the Influence of Climate Factors on Malaria Transmission Dynamics in North Kordofan State, Sudan. Advances in Infectious Diseases, 10, 189-199. https://doi.org/10.4236/aid.2020.105017

Received: August 28, 2020

Accepted: October 13, 2020

Published: October 16, 2020

Copyright $\odot 2020$ by author(s) and Scientific Research Publishing Inc. This work is licensed under the Creative Commons Attribution International License (CC BY 4.0).

http://creativecommons.org/licenses/by/4.0/ (c) (i) Open Access

\begin{abstract}
Background: Despite great efforts by the government to control malaria in Sudan, the disease is the most significant human disease and was widespread in North Kordofan State. Morbidity and mortality of the disease are increasing in the State. Usually, the disease reached its peak after rainy season. This study aims to estimate the role of climate factors on malaria transmission dynamic by modeling the relationship between malaria cases and climatic variables, such as rainfall, relative humidity, and temperature, in Kordofan State. Methods: We used Pearson correlation coefficient and an ordinary least square method to assess this relationship. Results: The results show that there are statistically significant associations between malaria cases and rainfall, relative humidity, and minimum temperature ( $\mathrm{P}$-value $<0.001)$. The regression analysis results suggest that the appropriate model for predicting malaria incidence includes malaria cases lagged by one month, maximum temperature, and minimum temperature. This model explained $72 \%$ of the variance in monthly malaria incidence. Conclusion: The results of this study suggest that climatic factors have potential use for malaria prediction in the State.
\end{abstract}

\section{Keywords}

Malaria Transmission, Climatic Factors, North Kordofan, Sudan

\section{Background}

Malaria is caused by parasites of the genus of plasmodium and is transmitted through a bite of female anopheles mosquitoes [1]. Malaria is world's most important vector-borne disease and is the leading cause of death among children under the age of five, a major cause of adult morbidity, and a major cause of loss 
of working days due to illness. Pregnant women and children are the two groups most at risk for the disease. Malaria is endemic in the poorest countries in the world. There were 228 million clinical cases worldwide in 2018, and nearly $85 \%$ of these cases were in Africa and India [2]. Variation in climatic circumstances, such as temperature, rainfall patterns, and relative humidity, has a profound effect on the survival of mosquitoes and on the growth of malaria parasites in mosquitoes. Consequently, these climatic factors can also influence the transmission of malaria [3] [4] along with public health services, insecticide usage, drug resistance rates, and human population movements [5]. Nutrition has also been shown to affect malaria transmission, especially in children and pregnant women [6] [7].

Several studies have shown the influence of variations in these climatic factors on malaria transmission. Associations between climate factors and the number of malaria cases have been reported recently in many areas in Africa [8] [9]. Conversely, some studies have reported that there is no significant association between climatic trends and the number of malaria cases in East Africa where cases of malaria increase every year [10]. Some studies found that only minimum temperature affects malaria transmission [11]. Huang et al. found a positive effect of rainfall on malaria transmission [12] while Mabaso et al. suggested a combination of rainfall, minimum and maximum temperature affect malaria transmission [13].

Environmental changes such as deforestation and housing structure could also influence malaria transmission as they enhance mosquito breeding conditions [14]. Ye et al. found that environmental factors play in important role in distribution, abundance, and survival of the malaria vector [15].

To develop a useful statistical model to help explain the relationship between malaria and climatic variables, several methods have been used in the literature. Riedel et al. used logistic regression to assess the relationship they between low altitude and high day and night land surface temperatures as the factors for high malaria transmission [16]. Zacarias and Andersson aggregated malaria accounts, in Mozambique, over a two-year period and used a Bayesian hierarchical model. Their findings suggest that the strength of the relationship between the number of malaria cases and selected climatic variables varied between consecutive years [17]. A study in Indonesia used geographically weighted regression and ordinary least squares (OLS) to model the association between the number of malaria cases and some environmental factors, such as the distance from forest and rainfall. The study found strong relationship between these variables and malaria cases [18]. Understanding the relationship between malaria transmission and environmental factors will help in achieving better malaria control. The aim of this study was to determine some linkage between the malaria transmission and climatic variables such as rainfall, relative humidity, and temperature, in Kordofan State, West of Sudan. We analyze malaria cases using Pearson correlation coefficient and OLS method. 


\section{Malaria Transmission}

Malaria spreads after a mosquito becomes infected with the disease by biting an infected human. The infected mosquito then transmits the disease when it bites an uninfected human and the malaria parasites move to the liver. When a parasite matures, it leaves the liver and infects the red blood cells [19]. Temperature is one of the climatic factors, known to play an important role in the development of the parasite [20] [21] [22]. The transmission of malaria in Sudan is seasonal, with the peak during autumn rainy season, depends on climatic conditions which can powerfully affect the number and survival of mosquitoes [18]. Therefore, it is possible for malaria epidemic outbreaks to occur in areas with vulnerable populations having little or no immunity to malaria. In addition, unexpected meteorological phenomenon and human activities affecting the environment, such as, deforestation and agricultural irrigation could affect malaria transmission and lead to epidemic outbreaks [23]. The forecasting of the consequences of climate change in malaria transmission is of great importance to achieving better malaria control and avoid epidemic outbreaks. The dynamic process of malaria transmission includes numerous interlinked variables, from uncontrollable environmental conditions to man-made natural disturbances [24]. In this paper we study the linkage of malaria transmission with climatic factors (temperature, relative humidity, and rainfall) in Kordofan State where most people are in extreme poverty.

\section{Materials and Methods}

\subsection{Study Area}

This study was carried out in North Kordofan State, Sudan. This state lies in the central-western part of country at the northern edge of the savannah belt. The area of Kordofan is about $244.700 \mathrm{~km}^{2}$; with a population of 2,920,000 representing approximately $7.5 \%$ of the total population Sudan. The State is divided into 9 localities 45 units. El-Obeid is the capital of the state (see Figure 1). The economic structure based largely on agriculture, focusing on growing crops and livestock breeding. However, most of the population are living in poverty or far below reasonable standards of living as urban deprivation is widespread. Rainfall in the State is sporadic in occurrence with a rate between $150 \mathrm{~mm}$ in the north and $850 \mathrm{~mm}$ in the south of the State. There are recurrent droughts at varying length and severity (e.g., 1968-1974; 1983-1985 and 1990-1991, 2000, 2003, and 2009). Abnormally heavy rains with damaging effects on the environment and economy of the State occurred in 1988, 1994, 1998, 2009, 2012, and 2015. The State is characterized by varied physical and cultural diversity, which have led to distinct resource and land use patterns. Broad localized ecological divisions have been created because of unbalanced development leading to seriously negative impacts including regular malaria outbreaks. Forecasting for such outbreaks could aid the State in the management of health problems. 


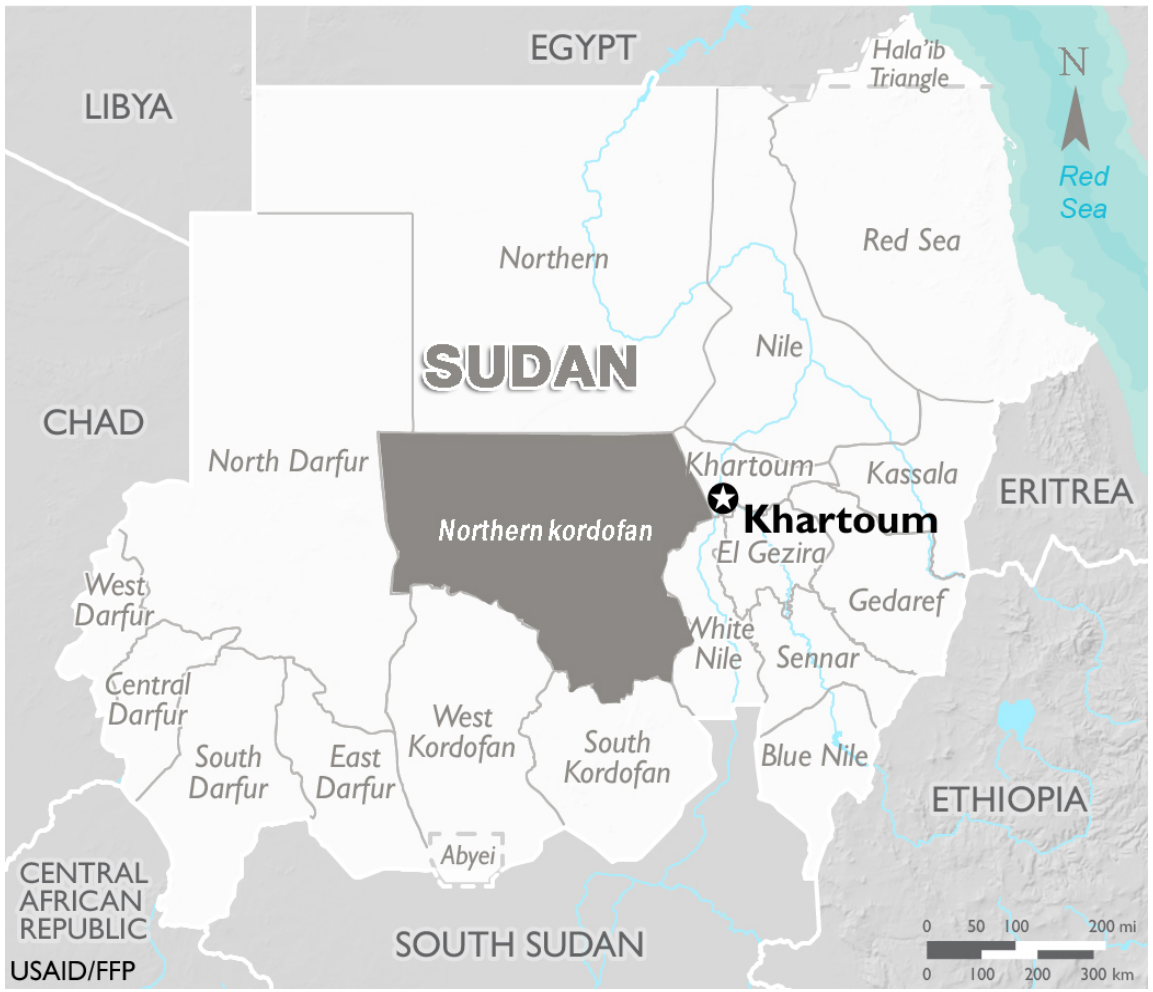

Figure 1. The administration map of Sudan, Kordofan State in black color.

\subsection{Statistical Analysis of Data}

Data on monthly malaria cases from 2009 to 2018 were obtained from the Federal Ministry of Health, Sudan. Data on meteorological factors, namely, rainfall, relative humidity, and temperature were obtained from the Sudan Meteorological Authority. The set of data that we collect were stored in an Excel workbook for statistical analysis and to generate the time series plot. We used SPSS software for regression and correlation analyses. We modeled the influence of selected climatic variables on the incidence of malaria by considering the number of malaria cases as independent variable, and temperature, relative humidity, and rainfall as explanatory variables. We performed the liner regression analysis using OLS methods. Further testing was done to determine how changes in climatic variables were associated with changes in malaria cases. Pearson correlation coefficient was used to evaluate this association. Variance inflation factor (VIF) was calculated for each independent variable to assess the correlation of each independent variable with the other variables (multicollinearity problem) in the model. Using VIF helped to identify the best regression model by removing or consolidation variables to capture their joint effect. The general rule of thumb is that VIFs between 5 and 10 indicate critical levels of multicollinearity where the coefficients are poorly estimated, while VIFs exceeding 10 are signs of serious multicollinearity requiring correction [25].

Mathematically, the general form of multiple regression is

$$
Y=\beta_{0}+\beta_{1} X_{1}+\beta_{2} X_{2}+\cdots+\beta_{k} X_{k}+\epsilon_{i}
$$


for $i=1,2, \cdots, n$, where $\beta_{0}, \beta_{1}, \beta_{k}$ are parameters of the model and $\epsilon_{i}$ denotes the error term (the deviation of the observation from linear relationship).

The VIF for the $j$ th predictor could be defined as follows:

$$
V I F_{j}=1 /\left(1-R_{j}^{2}\right)
$$

where $R_{j}^{2}$ is the coefficient of determination obtained by regressing the $\mathrm{jth}$ predictor on the remaining predictors.

The variables we have in the regression model are: $Y_{t}$ the number of malaria cases at time $\mathrm{t}$; $\max \left({ }^{\circ} \mathrm{C}\right)$, the maximum temperature; $\min \left({ }^{\circ} \mathrm{C}\right)$, the minimum temperature; R.h (\%), relative humidity; and rainfall ( $\mathrm{mm})$. We used a stepwise regression method to calculate all possible regression models using a set of our climatic variables. This method is used to determine which explanatory variables are relevant from a set of candidate explanatory variables. Then we chose the appropriate model which overcomes the multicollinearity problem (low $V I F_{j}$ ) with a high value of $R^{2}$.

\section{Results}

A total of 1,087,882 malaria cases were reported in North Kordofan during the study period 2009-2018. The average monthly number of malaria cases was 9066 (range: 1244-26,549). The annual trend of total malaria cases is demonstrated in Figure 2. Generally, there was a rapid increase in malaria cases from 2012 to 2018. However, the number of malaria cases decreased in the 2013, but markedly increases in 2014 before reaching its peak in 2018.

Figure 3 presents the mean monthly malaria cases and seasonal variation in North Kordofan State during from 2009 to 2018. The occurrence of malaria is nearly continuous throughout the year with a maximum number of malaria cases in rainy season (Jun-Sep). This seasonal trend of malaria suggests that autumn (Jun, July, August, September) is the most intense season of malaria infection. The lowest number of malaria cases was observed in winter (January, February, and March).

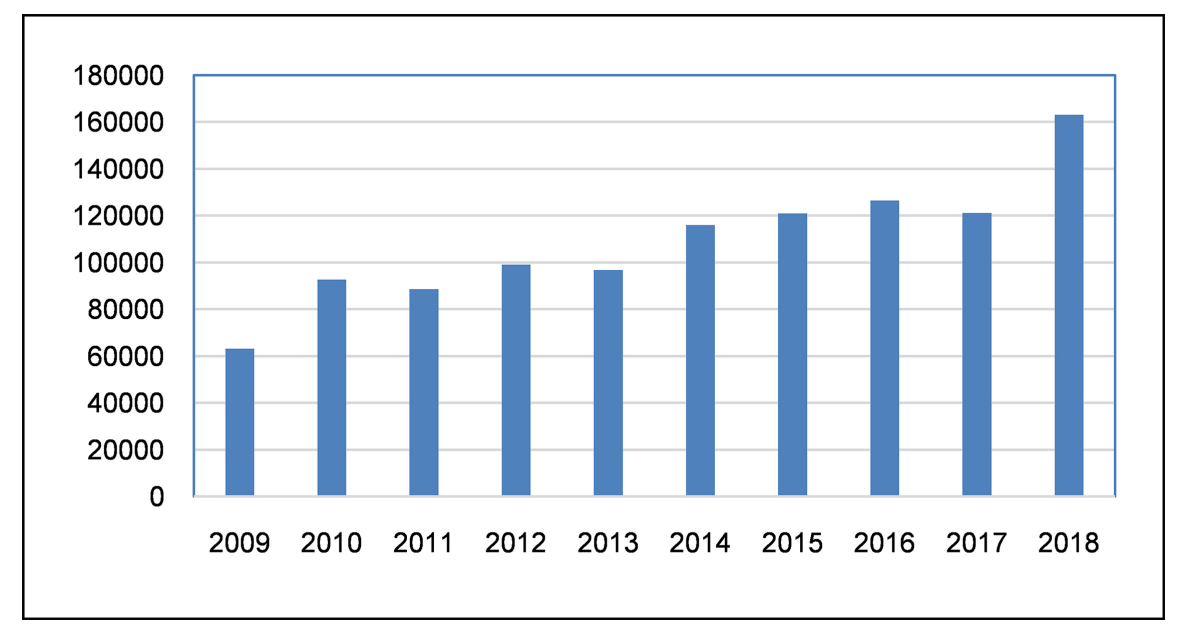

Figure 2. Annual trends of total malaria cases in North Kordofan, 2009-2018. 
Figure 4 presents the time series plot of malaria cases and climatic variables (maximum and minimum temperature, rainfall, and relative humidity) from 2009 to 2018 . The fluctuation in malaria cases with rainfall and relative humidity does exist. However, maximum and minimum temperature appears to be not as closely tied to malaria cases.

Table 1 presents descriptive statistics of climatic factors during 2009-2018. The monthly mean maximum temperature ranged from as low as $24.8^{\circ} \mathrm{C}$ in 2006 to as high as $40.6^{\circ} \mathrm{C}$ in 2011 . The greatest amount of rainfall is $137.50 \mathrm{~mm}$ occurred in Aug. 2010.

Table 2 illustrates the results of the Spearman correlation coefficient analysis, which examines the relationship between climatic variables and malaria cases. The results show that there was a significant positive relationship between malaria cases and minimum temperature, relative humidity, and monthly total rainfall (P-value $<0.001)$. There was no significant relationship between malaria cases and maximum temperature. To study the relevance lags of accumulated number of malaria cases, we shifted one month behind the monthly malaria cases $\left(Y_{t-1}\right)$. The time shift revealed there is a significant serial correlation of the number of malaria cases $(\mathrm{P}$-value $<0.001)$.

The relationships between malaria and climatic variables were further checked by linear regression analyses. Multiple regression analysis was used to predict the number of malaria cases based on climatic factors.

Table 3 contains the results of analysis of the multiple regression analysis. The coefficient of multiple determination in model 1 and model 2 are equal $\left(R^{2}=\right.$ 0.72). The values for VIFs in the model 1 lower than 5 for all explanatory variables while some VIFs for the model 2 are greater than 5 . This result suggests that model 1 reduces multicollinearity between explanatory variables. Using these results, the model in Equation (1) can be solved to give the appropriate regression model for predicting the number of malaria cases as follows:

$$
Y_{t}=21410.48+0.51 *\left(Y_{t-1}\right)-977.55 *\left(\max \left({ }^{\circ} \mathrm{C}\right)\right)+822.65 *\left(\min \left({ }^{\circ} \mathrm{C}\right)\right)
$$

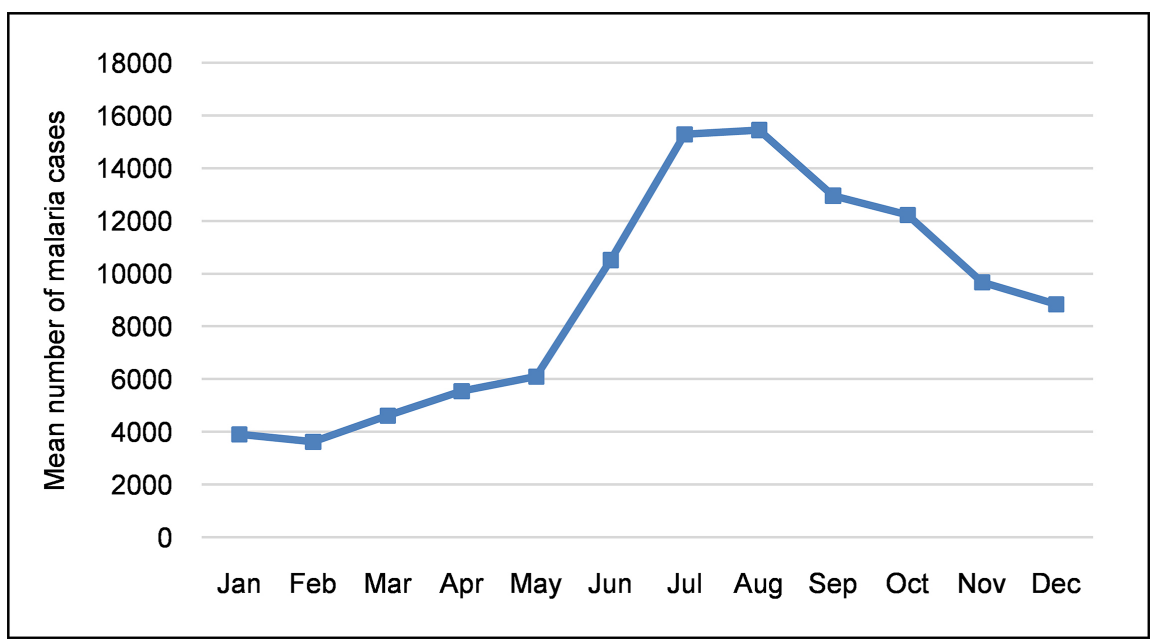

Figure 3. Mean monthly malaria cases and seasonal variation, 2009-2018. 
The P-values for all independent variable were less than 0.0001, which suggests that the three independent variables account for a significant part of the variation in $Y_{t}$.

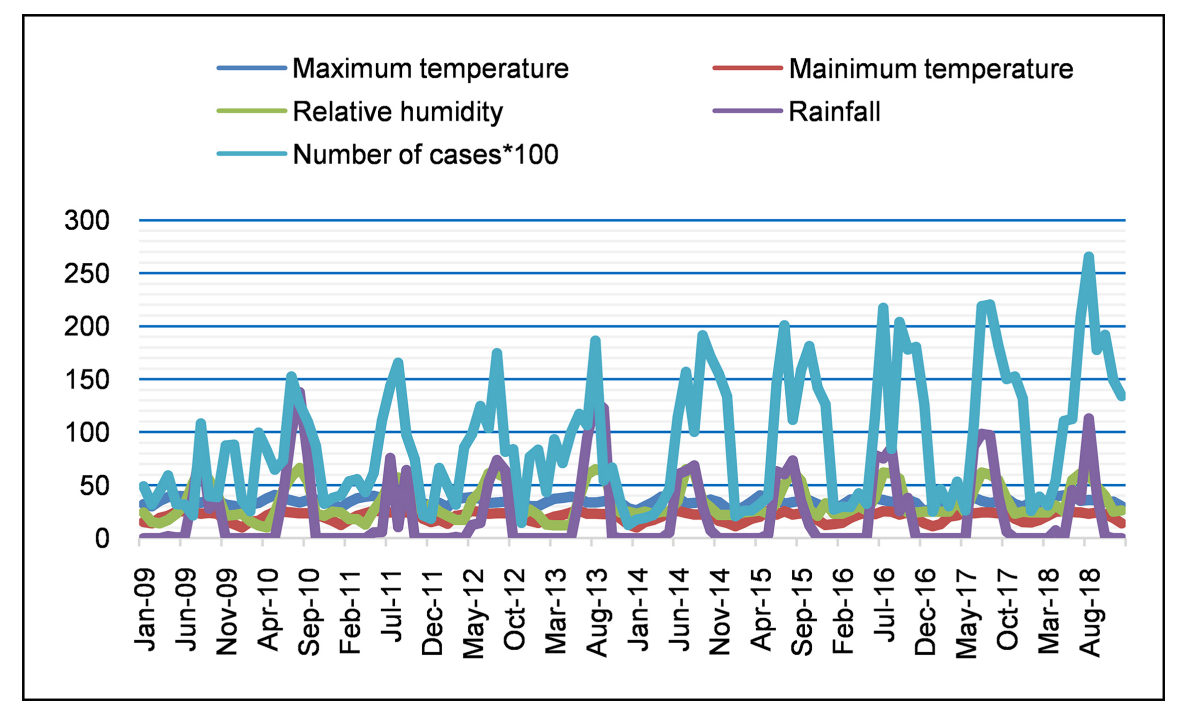

Figure 4. Annual climatic factors variation and malaria incidence, 2009-2018.

Table 1. Descriptive statistics for climatic variables in North Kordofan State, 2009-2018.

\begin{tabular}{ccccc}
\hline Variables & Minimum & Maximum & Mean & Std. Deviation \\
\hline Max $\left({ }^{\circ} \mathrm{C}\right)$ & 24.80 & 40.60 & 34.66 & 3.54 \\
Min $\left({ }^{\circ} \mathrm{C}\right)$ & 10.00 & 25.90 & 20.45 & 4.33 \\
R.h (\%) & 10.00 & 67.00 & 33.64 & 16.03 \\
Rainfall $(\mathrm{mm})$ & 0.00 & 137.50 & 22.34 & 35.29 \\
\hline
\end{tabular}

Max $\left({ }^{\circ} \mathrm{C}\right)$ : Maximum temperature, Min $\left({ }^{\circ} \mathrm{C}\right)$ : Minimum temperature $\left({ }^{\circ} \mathrm{C}\right)$; and R.h (\%): Relative humidity (\%).

Table 2. Correlation between malaria cases and climatic variables in North Kordofan, 2009-2019.

\begin{tabular}{ccc}
\hline Variables & $\left(Y_{0}\right)$ & $\left(Y_{t-1}\right)$ \\
\hline$\left(Y_{0}\right)$ & 1 & $0.644^{* *}$ \\
$\left(Y_{t-1}\right)$ & $0.644^{* *}$ & 1 \\
$\operatorname{Max}\left({ }^{\circ} \mathrm{C}\right)$ & 0.070 & $0.331^{* *}$ \\
$\operatorname{Min}\left({ }^{\circ} \mathrm{C}\right)$ & $0.381^{* *}$ & $0.544^{* *}$ \\
$\operatorname{R.h}(\%)$ & $0.545^{* *}$ & $0.505^{* *}$ \\
$\operatorname{Rainfall}(\mathrm{mm})$ & $0.517^{* *}$ & $0.521^{* *}$ \\
\hline
\end{tabular}

${ }^{*}$ Correlation is significant $(\mathrm{r})$ at the 0.01 level (2-tailed, $Y_{0}$ : the number of malaria cases at the base month, $Y_{\dot{r}}$ the number of malaria cases at time (month) t, $\operatorname{Max}\left({ }^{\circ} \mathrm{C}\right)$ : Maximum temperature, Min $\left({ }^{\circ} \mathrm{C}\right)$ : Minimum temperature $\left({ }^{\circ} \mathrm{C}\right)$; and R.h (\%): Relative humidity (\%). 
Table 3. Multiple linear regression for monthly total malaria cases occurrence and climatic variables, North Kordofan State during the period, 2009-2018.

\begin{tabular}{|c|c|c|c|c|c|c|}
\hline Model & Variables & B & Beta & P-Value & $\begin{array}{c}\text { Collinearity } \\
\text { Statistics } \\
\text { VIF }\end{array}$ & $\begin{array}{c}\text { Coefficient } \\
\text { of multiple } \\
\text { determination } \\
\left(\mathrm{R}^{2}\right)\end{array}$ \\
\hline \multirow{4}{*}{ Model 1} & (Constant) & $21,410.48$ & & 0000 & 1.51 & \multirow{4}{*}{0.72} \\
\hline & $\left(Y_{t-1}\right)$ & 0.51 & 0.52 & 0.00 & 3.30 & \\
\hline & $\operatorname{Max}\left({ }^{\circ} \mathrm{C}\right)$ & -977.55 & -0.58 & 0.00 & 4.17 & \\
\hline & $\operatorname{Min}\left({ }^{\circ} \mathrm{C}\right)$ & 822.65 & 0.59 & 0.00 & 1.51 & \\
\hline \multirow{7}{*}{ Model 2} & (Constant) & $18,107.24$ & & 0.00 & & \multirow{7}{*}{0.72} \\
\hline & $\left(Y_{t-1}\right)$ & 0.50 & 0.50 & 0.00 & 1.64 & \\
\hline & $\operatorname{Max}\left({ }^{\circ} \mathrm{C}\right)$ & -806.94 & -0.48 & 0.00 & 5.10 & \\
\hline & & & & & & \\
\hline & $\operatorname{Min}\left({ }^{\circ} \mathrm{C}\right)$ & 646.90 & 0.46 & 0.02 & 8.30 & \\
\hline & R.h (\%) & 31.94 & 0.09 & 0.55 & 4.87 & \\
\hline & Rainfall (mm) & 3.41 & 0.02 & 0.87 & 3.77 & \\
\hline
\end{tabular}

$Y_{\dot{t}}$ the number of malaria cases at time (month) t, $\operatorname{Max}\left({ }^{\circ} \mathrm{C}\right):$ Maximum temperature, $\operatorname{Min}\left({ }^{\circ} \mathrm{C}\right)$ : Minimum temperature $\left({ }^{\circ} \mathrm{C}\right)$; and R.h (\%): Relative humidity (\%).

\section{Discussion}

This study investigated the influence of climatic factors on malaria parasite transmission, in North Kordofan State, Sudan. It is well known that the relationship between malaria outbreaks and climatic factors is indirect and complex. The climatic variability that affects mosquito vectors, malaria parasites, and intrinsic of malaria transmission dynamics contributes significantly to malaria transmission [26].

These results suggest that increased rainfall increases the number of malaria cases. This effect can be explained by the large amount of swamp water in the Kordofan State during an autumn season. The changes of temperature in the Kordofan justify the significant relationship between malaria and minimum temperature [27]. These results suggest that climatic factors have potential use for malaria prediction in the State.

The significant serial correlation of the number of malaria cases (Table 2, $r=$ 0.644) indicates that the variable "the number of cases in this month" affects malaria transmission in next month. This means that malaria in any month could be a potential variable for malaria prediction and future outbreaks. Our results showed that monthly minimum temperatures were the strongest predictor of malaria incidence, followed by relative humidity. The strong positive correlation between total rainfall and relative humidity shown in our data (Table 2) support the local knowledge that in North Kordofan autumn season is the season of malaria. This finding agrees with other findings that the effect of rainfall 
is more immediate in warmer temperatures [28].

Based on the coefficient of determination and VIF, the best regression model was the model with independent variables: malaria cases lagged by one month $\left(Y_{t-1}\right)$, maximum temperature, and minimum temperature. This model had the best overall performance $\left(R^{2}=0.72\right)$ without multicollinearity problem (VIF < 5). This model shows that $72 \%$ of the variation in the number of malaria cases is explained by a one-month lag of malaria cases, maximum temperature and minimum temperature. This result suggests that maximum temperature and minimum temperature affect the malaria transmission significantly.

\section{Conclusions}

In this paper, we model the influence of selected climatic variables on the incidence of malaria in Kordofan State, Sudan. We employed correlation coefficient and regression analyses. Most of the malaria cases in the study area are reported to have occurred during rainy months compared to the dry season (Figure 3 ). The results revealed that the minimum temperature, relative humidity, and monthly total rainfall have an influence on malaria cases. These results suggest that the disturbances in climatic factors affect the transmission dynamics of malaria. Further research should be undertaken at national scale based on environmental and socio-economic factors in addition to consideration of vulnerability to malaria. Modeling of theses remains to be the solution for the health problems in the State and help to reduce the risk of malaria outbreak in the country.

For the government to reduce malaria transmission, the WHO goal of malaria control should be carried out through prevention interventions such as distribution of insecticide-treated nets, intermittent preventive treatment of malaria and Indoor residual spraying.

There may be a limitation of this research that some bias of the prediction model as rainfall is significantly correlated with the number of malaria cases, but due to the multicollinearity problem of regression model, the best model is Model 2 in which rainfall is excluded.

\section{Acknowledgements}

The author would like to thank King Abdulaziz University (KAU) for the support to conduct the study. The author is grateful to Dr Abdelmgid O., for his excellent technical editing of the paper.

\section{Funding Sources}

This research did not receive any specific grant from funding agencies in the public, commercial, or not-for-profit sectors.

\section{Conflicts of Interest}

The author declares that he has no known competing financial interests or per- 
sonal relationships that could have appeared to influence the work reported in this paper.

\section{References}

[1] Alemu, A., Abebe, G., Tsegaye, W. and Golassa, L. (2011) Climatic Variables and Malaria Transmission Dynamics in Jimma Town, South West Ethiopia. Parasites \& Vectors, 4, Article No. 30. https://doi.org/10.1186/1756-3305-4-30

[2] WHO (2019) World Malaria Report 2018. WHO, Geneva.

[3] Craig, M.H., Kleinschmidt, I., Nawn, J.B., Le Sueur, D. and Sharp, B.IL. (2004) Exploring 30 Years of Malaria Case Data in Kwazulu-Natal, South Africa: Part I. The Impact of Climate Factors. Tropical Medicine \& International Health, 9, 1247-1257. https://doi.org/10.1111/j.1365-3156.2004.01340.x

[4] Hoshen, M.B and Morse, A.P. (2004) A Weather Driven Model of Malaria Transmission. Malaria Journal, 3, Article No. 32.

[5] Hales, S., Edwards, S.J. and Kovats, R.S. (2003) Impact on Health of Climate Extremes. In: WHO, Ed., Climate Change and Human Health: Risks and Responses, WHO, Geneva, 79-102.

[6] Saad, A.A., Doka, Y.A., Osman, S.M., Magzoub, M., Ali, N.I. and Adam, I. (2013) Zinc, Copper and C-Reative Protein in Children with Severe Plasmodium Falciparum Malaria in an Area of Unstable Malaria Transmission in Eastern Sudan. Journal of Tropical Pediatrics, 59, 150-153. https://doi.org/10.1093/tropej/fms056

[7] Bader, E., Alhaj, A.M., Hussan, A.A. and Adam, I. (2010) Malaria and Still Birth in Omdurman Maternity Hospital, Sudan. International Journal of Gynecology and Obstetrics, 109, 144-146. https://doi.org/10.1016/j.ijgo.2009.11.022

[8] Githeko, A.K. and Ndegwa, W. (2001) Predicting Malaria Epidemics in the Kenyan Highlands Using Climate Data: A Tool for Decision Makers. Global Change and Human Health, 2, 54-63. https://doi.org/10.1023/A:1011943131643

[9] Bouma, M.J. and Van Der Kaay, H.J. (1995) Epidemic Malaria in India's Thar Desert. The Lancet, 373, 132-133.

[10] Hay, S. I., Cox, J., Rogers, D., et al. (2002) Climate Change and the Resurgence of Malaria in the East African Highlands. Nature, 415, 905-909.

https://doi.org/10.1038/415905a

[11] Nkurunziza, H., Gebhardt, A. and Pilz, J. (2010). Bayesian Modelling of the Effect of Climate on Malaria in Burundi. Malaria Journal, 9, Article No. 114. https://doi.org/10.1186/1475-2875-9-114

[12] Huang, F., Zhou, S.S., Zhang, S.S., Zhang, H.W. and Li, W.D. (2011) Meteorological Factors-Based Patio-Temporal Mapping and Predicting Malaria in Central China. The American Journal of Tropical Medicine and Hygiene, 85, 560-567. https://doi.org/10.4269/ajtmh.2011.11-0156

[13] Mabaso, M.L.H., Vounatsou, P., Midzi, S., Da Silva, J. and Smith, T. (2006) Spatio-Temporal Analysis of the Role of Climate in Inter-Annual Variation of Malaria Incidence in Zimbabwe. International Journal of Health Geographics, 5, Article No. 20. https://doi.org/10.1186/1476-072X-5-20

[14] Raso, G, Schur, N., Utzinger, J., et al. (2012) Mapping Malaria Risk among Children in Cote d'Ivoire Using Bayesian Geo-Statistical Models. Malaria Journal, 11, Article No. 160. https://doi.org/10.1186/1475-2875-11-160

[15] Ye, Y., Louis, V.R., Simboro, S. and Sauerborn, R. (2007) Effect of Meteorological Factors on Clinical Malaria Risk among Children: an Assessment Using Vil- 
lage-Based Meteorological Stations and Community-Based Parasitological Survey. BMC Public Health, 7, Article No. 101. https://doi.org/10.1186/1471-2458-7-101

[16] Riedel, N., Vounatsou, P., Miller, J.M., et al. (2010) Geographic Patterns and Predictors of Malaria Risk in Zambia: Bayesian Geostatistical Modelling of the 2006 Zambia National Malaria Indicator Survey. Malaria Journal, 9, Article No. 37.

[17] Zacarias, O. and Andersson, M. (2010) Mapping Malaria Incidence Distribution That Accounts for Environmental Factors in Maputo Province-Mozambique. Malaria Journal, 9, Article No. 79. https://doi.org/10.1186/1475-2875-9-79

[18] Hasyim, H., Nursafingi, A., Haque, U., et al. (2018) Spatial Modelling of Malaria Cases Associated with Environmental Factors in South Sumatra, Indonesia. Malaria Journal, 17, Article No. 87. https://doi.org/10.1186/s12936-018-2230-8

[19] Churcher, T.S., Sinden, R.E., Edwards, N.J., et al. (2017) Probability of Transmission of Malaria from Mosquito to Human Is Regulated by Mosquito Parasite Density in Naive and Vaccinated Hosts. PLoS Pathogens, 13, e1006108. https://doi.org/10.1371/journal.ppat.1006108

[20] Alonso, D., Bouma, M.J. and Pascual, M. (2011) Epidemic Malaria and Warmer Temperatures in Recent Decades in an East African Highland. Proceedings of the Royal Society B, 278, 1661-1669. https://doi.org/10.1098/rspb.2010.2020

[21] Parry, M., Canziani, O., Palutikof, J., Van Der Linden, P. and Hanson, C. (2007) Climate Change 2007: Impacts, Adaptation and Vulnerability. Cambridge University Press, Cambridge.

[22] Omumbo, J.A, Lyon, B., Waweru, S.M., Connor, S.J. and Thomson, M.C. (2011) Raised Temperatures over the Kericho Tea Estates: Revisiting the Climate in the East African Highland's Malaria Debate. Malaria Journal, 10, Article No. 12. https://doi.org/10.1186/1475-2875-10-12

[23] Kar, N.P., Kumar, A., Singh, O.P., Carlton, J.M. and Nanda, N. (2014) A Review of Malaria Transmission Dynamics in Forest Ecosystems. Parasites \& Vectors, 7, Article No. 265. https://doi.org/10.1186/1756-3305-7-265

[24] Wangroongsarb, P., Sudathip, P. and Satimai, W. (2012) Characteristics and Malaria Prevalence of Migrant Populations in Malaria-Endemic Areas along the Thai-Cambodian Border. Southeast Asian Journal of Tropical Medicine and Public Health. 43, 261-269.

[25] Makridakis, S., Wheelwright, S.C. and Hyndman, R.J. (2008) Forecasting Methods and Applications. John Wiley \& Sons, Hoboken.

[26] Abeku, T., Dexlas, S.J. and Borsboom, G.J. (2004). Effects of Meteorological Factors on Epidemic Malaria in Ethiopia: A Statistical Modeling Approach Based on Theoretical Reasoning. Parasitology, 128, 85-96. https://doi.org/10.1017/S0031182004005013

[27] Aal, R.A. and Elshayeb, A.A. (2011) The Effects of Climate Changes on the Distribution and Spread of Malaria in Sudan. American Journal of Environmental Science and Engineering, 1, 15-20. https://doi.org/10.5923/j.ajee.20110101.03

[28] Teklehaimanot, H.D., Lipsitch, M., Teklehaimanot, A. and Schwartz, J. (2004) Weather-Based Prediction of Plasmodium Falciparum Malaria in Epidemic-Prone Regions of Ethiopia I. Patterns of Lagged Weather Effects Reflect Biological Mechanisms. Malaria Journal, 3, Article No. 41.

https://doi.org/10.1186/1475-2875-3-41 